\title{
Audit Sistem Informasi Inventory Pada PT. DP UTAN KAYU Dengan Framework Cobit 4.1
}

\author{
Jamal Maulana Hudin ${ }^{\star 1}$, Nia Anggraeny ${ }^{2}$, Dicky Prayudi ${ }^{3}$ \\ ${ }^{1}$ Sistem Informasi/Universitas Bina Sarana Informatika, Sistem Informasi/STMIK Nusa Mandiri ${ }^{2}$ \\ ,IImu Komputer/ Universitas Bina Sarana Informatika ${ }^{3}$ \\ e-mail: jamal.jml@bsi.ac.id¹,niaanggraenyh1997@gmail.com², dicki.dcd@bsi.ac.id ${ }^{3}$
}

\begin{abstract}
Abstrak
Penelitian ini akan Membahas bagaimana audit sistem informasi inventory pada Domino's Pizza Utan Kayu menggunakan COBIT 4 sub domain PO, Al, DS, ME. Pengambilan data dilakukan menggunakan wawancara dan kuisioner. Pertanyaan dari kuisioner dibuat berdasarkan aktivitas pada cobit 4.1, yang disebarkan pada karyawan yang ada di Domino's Pizza. Hasil penelitian menunjukkan bahwa hasil pengelolaan kuesioner mendapatkan nilai rata-rata untuk domain $P O$, $M E, A l, D S$ adalah 3,23 dari rentang 0 - 5 yang artinya penerapan sistem inventory pada Domino's Pizza telah dilakukan tetapi masih memerlukan proses tata kelola TI secara rutin dan pada hasil penelitian ini ditemukan bahwa pada domain PO1 dan ME 2 di Domino's Pizza telah sesuai ekspektasi yaitu pada level 4 Manage and Measurable tetapi domain lainnya masih menduduki level 3 yaitu Defined Process.
\end{abstract}

Kata kunci: Audit, Sistem Informasi Inventory, Level Maturity, COBIT 4.1

\begin{abstract}
This research will discuss how to audit information system inventory on Domino's Pizza Utan Wood using COBIT 4 sub Domains PO, Al, DS, ME. Data retrieval is conducted using interviews and questionnaire. Questions from the questionnaire were made based on the activity on the COBIT 4.1, which is distributed to employees who are in Domino's Pizza. The results showed that the survey management results received an average value for the $P O$ domain, $M E$, $A$ I, DS is 3.23 from the $0-5$ range which means the application of the inventory system in Domino's Pizza has been done but still requires the process of IT governance routinely and in the results of this study found that in the domain PO1 and ME 2 at Domino's Pizza has been as expected as at level 4 Manage and Measurable but the other domain still occupy level 3 of Defined Process.
\end{abstract}

Keywords: Audits, information system Inventory, Level Maturity, COBIT 4.1

\section{Pendahuluan}

Saat ini, ilmu pengetahuan dan teknologi menempati posisi yang sangat penting. Hampir semua sektor usaha membutuhkan suatu teknologi yang semakin canggih untuk menghadapi persaingan usaha yang sangat ketat sekarang ini. Perkembangan teknologi yang sangat pesat ini pun berpengaruh dalam dunia bisnis. Peran teknologi informasi dalam dunia bisnis sangat besar untuk meningkatkan efektivitas, produktivitas dan daya saing perusahaan.

Membangun suatu sistem informasi memerlukan pemahaman yang baik dan jelas mengenai sistem yang akan digunakan baik dalam prosedur sistem, input, output maupun halhal yang mempengaruhi kinerja sistem baik untuk jangka pendek maupun jangka [1].

Domino's pizza Utan Kayu Jakarta merupakan salah bisnis yang bergerak panjang dalam bidang makanan. Khususnya menyajikan hidangan siap saji (Fast food). Sebagai restaurant yang setiap hari menyajikan sebuah hidangan, tentunya persediaan bahan baku dan barang merupakan suatu masalah yang sangat penting. Oleh karena itu sebuah restaurant harus memiliki suatu sistem inventory atau biasa kita kenal dengan istilah sistem persediaan barang atau bahan. Karena sering terjadinya selisih antara stok inventory pada sistem dan stok fisik pada Domino pizza Utan Kayu maka salah satu solusinya adalah dengan menerapkan teknologi 
informasi pada sistem inventory agar informasi yang diperoleh menjadi lebih akurat dan cepat sehingga pengelolaan inventory menjadi lebih efektif dan efisien.

Inventory adalah material yang dipakai oleh perusahaan untuk menjalankan bisnisnya. Jika perusahaan memproduksi suatu barang atau jasa maka material tersebut digunakan untuk mendukung atau menyediakan kebutuhan produksi. Inventori bagi perusahaan adalah untuk mengantisipasi kebutuhan pelanggan [2]. Agar dapat menstabilkan barang dan bahan disebuah restaurant dibutuhkan data data yang konkret agar barang tidak kelebihan ataupun kekurangan.

\section{Metode Penelitian \\ 2.1 Audit Sistem Informasi}

Sistem informasi merupakan kombinasi dari manusia, fasilitas atau alat teknologi, media, prosedur dan pengendalian yang terlibat dalam suatu kegiatan dan melibatkan serangkaian proses dalam membantu pengambilan keputusan yang digunakan untuk mencapai suatu tujuan [3]. Audit merupakan Aktivitas pengumpulan dan pengujian data, yang dilakukan oleh pihak yang kompeten dan independent dalam rangka menentukan kesesuaian informasi yang diaudit dengan standar/kriteria yang telah ditetapkan untuk disampaikan kepada para pihak yang membutuhkan / berkepentingan [4]. Proses pengumpulan dan pengevaluasian bukti-bukti untuk menentukan apakah suatu sistem aplikasi komputerisasi telah menetapkan dan menerapkan sistem pengendalian intern yang memadai, semua aktiva dilindungi dengan baik / tidak disalahgunakan serta terjaminnya integritas data, keandalan serta efektifitas dan efisiensi penyelenggaraan sistem informasi berbasis komputer [5].

\subsection{Sistem Inventory}

Inventory adalah stok dari suatu item atau sumber daya yang digunakan dalam suatu organisasi perusahaan. Sistem inventory adalah sekumpulan kebijakan dan pengendalian yang memonitor tingkat inventory dan menentukan tingkat mana yang harus dijaga, bila stok harus diisi kembali dan berapa banyak yang harus dipesan. Sistem inventory akan memberikan kemungkinan struktur organisasi dan kebijakan operasi produksi, untuk menjaga dan mengawasi barang-barang untuk distok [7].

Dalam perusahaan perdagangan pada dasarnya hanya ada satu golongan inventory (persediaan), yang mempunyai sifat perputaran yang sama yaitu yang disebut "Merchandise Inventory" (persediaan barang dagangan). Persediaan ini merupakan persediaan barang yang selalu dalam perputaran, yang selalu dibeli dan dijual yang tidak mengalami proses lebih lanjut didalam perusahaan tersebut yang mengakibatkan perubahan bentuk dari barang yang bersangkutan [8].

\subsection{COBIT}

COBIT adalah cara atau metode yang dapat ditempuh untuk dapat menganalisa, mengembangkan, mempublikasikan, dan mempromosikan suatu otorisasi [6].

COBIT memiliki fungsi antara lain:[3]

1) Meningkatkan pendekatan / program audit

2) Mendukung audit kerja dengan arahan audit secara rinci

3) Memberikan petunjuk untuk IT governance

4) Sebagai penilaian benchmark untuk kendali sistem informasi / teknologi informasi

5) Meningkatkan kontrol sistem informasi / teknologi informasi.

6) Sebagai standarisasi pendekatan/ program audit

Aktivitas teknologi informasi pada COBIT 4.1 didefinisikan ke dalam 4 domain yaitu:[9]

1) Planning and Organization (PO)

Domain ini mencakup strategi dan taktik, dan perhatian atas identifikasi bagaimana $\mathrm{TI}$ secara maksimal dapat berkontribusi dalam pencapaian tujuan bisnis. Selain itu, realisasi dari visi strategis perlu direncanakan, dikomunikasikan, dan dikelola untuk berbagai perspektif yang berbeda. Terakhir, sebuah pengorganisasian yang baik serta infrastruktur teknologi harus di tempatkan di tempat yang semestinya

2) Acquisition and Implementation (AI)

Untuk merealisasikan strategi $\mathrm{TI}$, solusi $\mathrm{TI}$ perlu diidentifikasi, dikembangkan atau diperoleh, serta diimplementasikan, dan terintegrasi ke dalam proses bisnis. Selain itu,

REPOSITOR, Vol. 2, No. 10, Oktober 2020, Pp. 1359-1367 
perubahan serta pemeliharaan sistem yang ada harus di cakup dalam domain ini untuk memastikan bahwa siklus hidup akan terus berlangsung untuk sistem ini.

3) Delievery and Support (DS)

Domain ini memberikan fokus utama pada aspek penyampaian/pengiriman dari $\mathrm{TI}$. Domain ini mencakup area-area seperti pengoperasian aplikasi-aplikasi dalam sistem TI dan hasilnya, dan juga, proses dukungan yang memungkinkan pengoperasian sistem $\mathrm{TI}$ tersebut dengan efektif dan efisien. Proses dukungan ini termasuk isu/masalah keamanan dan juga pelatihan.

4) Monitoring and Evaluation (ME)

Semua proses IT perlu dinilai secara teratur sepanjang waktu untuk menjaga kualitas dan pemenuhan atas syarat pengendalian. Domain ini menunjuk pada perlunya pengawasan manajemen atas proses pengendalian dalam organisasi serta penilaian independen yang dilakukan baik auditor internal maupun eksternal atau diperoleh dari sumber-sumber alternatif lainnya

\subsection{Maturity Level}

Yang menjadi tolak ukur dalam standar COBIT adalah maturity level yang digunakan untuk menentukan sampai mana tingkat proses dan pengelolaan TI tersebut [10].

Tingkat Kematangan (Maturity Level) merupakan salah satu pengukuran yang dijadikan standar COBIT. Pengukuran tingkat kematangan ini diatur untuk tingkat manajemen dan memungkinkan para manajer mengetahui bagaimana pengelolaan dan proses-proses $\mathrm{TI}$ di organisasi tersebut sehingga bisa diketahui pada tingkatan mana pengelolaannya [11].

Tabel 1. Level Kematangan Framework COBIT 4.1
\begin{tabular}{|l|l|}
\hline $\begin{array}{c}\text { Indeks } \\
\text { Kematangan }\end{array}$ & \multicolumn{1}{c|}{ Level Kematangan } \\
\hline $0-0.49$ & $0-$ Non-Existent \\
\hline $0.50-1.49$ & $1-$ Initial/Ad Hoc \\
\hline $1.50-2.49$ & $2-$ Repeatable but Intuitive \\
\hline $2.50-3.49$ & $3-$ Defined Process \\
\hline $3.50-4.49$ & $4-$ Managed and Measurable \\
\hline $4.50-5.00$ & $5-$ Optimized \\
\hline
\end{tabular}

generic maturity model[12]

0 - Non-existent (Management processes are not applied at all) Tidak terdapat proses sama sekali. Organisasi/perusahaan yang belum menyadari bahwa adanya permasalahan yang harus dan mesti dikaji.

1 - Initial/Ad Hoc (Processes are ad hoc and disorganized) Ada bukti bahwa perusahaan menyadari adanya permasalahan yang harus dikaji, tetapi belum ada standarisasi. Namun, terdapat pelaksanaan pendekatan ad hoc yang berkecenderungan untuk diimplementasikan yang memiliki ketersesuaian dengan kasus. Pendekatan manajemen secara umum dilakukan dengan tidak terstruktur.

2 - Repeatable but Intuitive (Processes/allow a regular pattern) Proses yang ada telah berkembang sampai kepada tahap dimana prosedur yang serupa telah diikuti oleh para pekerja yang menjalankan tugas ini. Tidak adanya komunikasi atau training yang dilakukan dengan formal tentang standard procedure dan tanggung jawabnya yang jatuh kepada individu. Sering eror dan adanya ketergantungan yang sangat tinggi terhadap individu.

3 - Defined Process (Processess are documented and communicated) Prosedur yang terlaksana telah didokumentasi, distandarisasi dan dikomunikasikan melalui pelaksanaan training. Proses tersebut wajib diikuti. Tetapi, penyimpangannya tidak dapat terdeteksi. Prosedur tersebut tidak lengkap, akan tetapi terformalisasi pada practice yang berjalan sekarang.

4 - Managed and measurable (Processess are monitored anmeasured) Manajemen mengawasi dan mengukur tingkat kesesuaian proses yang berjalan dengan prosedur serta mengambil tindakan apabila proses terlihat tidak berjalan secara efektif. Pengembangan process dilakukan secara konstan dan menyediakan / memberikan good practice. Otomasi dan alat bantu digunakan dalam cara tertentu. 
5 - Optimised Proses (Good practices are followed and automated) yang terlaksana telah didesain, dipilih, dan diatur sampai ke level pelaksanaan yang baik, berdasarkan hasil dari pengembangan atau perbaikan yang berkelanjutan serta model kematangan terhadap organisasi / perusahaan lain. IT dipergunakan secara terintegrasi untuk dapat mengotomasikan alur kerja, menyediakan tools support yang bertujuan meningkatkan nilai quality dan efektivitas, serta membuat perusahaan mudah beradaptasi.

\subsection{Tahapan Penelitian}

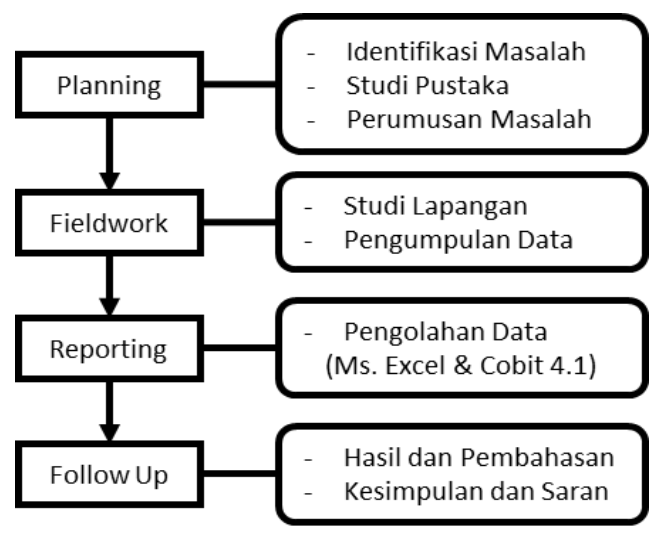

Gambar 1. Alur Tahapan Penelitian

Berikut keterangan dari tahapan penelitian diatas:

1) Identifikasi Masalah

Penulis melakukan penelitian tentang sistem audit inventory pada Domino's pizza Utan Kayu Jakarta.

2) Studi Pustaka

Pada tahap ini, dikakukan untuk memperdalam teori maupun metode yang akan digunakan dalam menyelesaikan masalah yang telah ditentukan sebelumnya. Teori yang dibutuhkan diperoleh dari jurnal, buku, catatan maupun literatur lainnya.

3) Perumusan Masalah

Pada tahap ini, penulis membahas bagaimana kinerja sistem inventory yang ada di Domino's Pizza Utan Kayu Jakarta apakah sudah sesuai dengan prosedur yang sudah di tetapkan pada awal penerapannya.

4) Studi Lapangan

Melakukan pencarian sumber data kepada pihak-pihak yang berkaitan dengan sistem inventory pada Domino's Pizza Utan Kayu Jakarta baik melalui kesioner ataupun wawancara.

5) Pengumpulan Data

Pengumpulan data dilakukan dengan membagikan kuesioner kepada karyawan Domino's Pizza Utan Kayu Jakarta. Hal ini dilakukan bersamaan dengan studi lapangan guna menghemat waktu,biaya serta tenaga.

6) Pengolahan Data Dengan Mengunakan Ms. Excel 2016.

Pengolahan data tahap ini bertujuan untuk mendapatkan mengolah dari hasil penyebaran kuesioner kepada responden sehingga didapatkan hasil data yang siap diolah menggunakan framework COBIT 4.1.

7) Pengolahan Data Dengan Menggunakan Metode / Framework COBIT 4.1

Pada tahap ini bertujuan untuk menghitung data hasil perhitungan Ms. Excel 2016 agar didapatkan hasil current maturity, expected maturity, dan gap/ selisih sehingga didapatkan hasil dari proses audit sistem inventory yang ada pada Domino's Pizza Utan Kayu Jakarta.

8) Hasil dan Pembahasan

Tahap selanjutnya yang dilakukan adalah menganalisis hasil pengolahan data dengan menggunakan framework COBIT 4.1 ke tahap yang lebih mendalam guna mendapatkan

REPOSITOR, Vol. 2, No. 10, Oktober 2020, Pp. 1359-1367 
hasil hasil audit sistem informasi inventory yang lebih akurat dan sesuai dengan keadaan aslinya.

9) Kesimpulan dan Saran

Tahap terakhir dari penelitian ini yaitu menarik kesimpulan berdasarkan dari hasil pengolahan dan analisis data bersarkan domain COBIT 4.1, serta memberikan saransaran yang dapat dijadikan acuan kepada manejemen Domino's Pizza Utan Kayu Jakarta maupun pihak lain yang berkepentingan.

\section{Hasil Penelitian dan Pembahasan}

\subsection{Analisa Data}

Data penelitian diperoleh dari penyebaran kuesioner. Analisis yang dilakukan terhadap data yang diperoleh, ditinjau secara kualitatif dan kuantitatif yang mencakup tentang penerapan dan pengukuran kinerja serta mengetahui tingkat kematangan terhadap sistem informasi inventory pada Domino's Pizza saat ini dengan tingkat kematangan yang diharapkan. Kemudian data yang telah diterima dari hasil kuisioner tersebut diolah dengan penerapan metode framework COBIT 4.1 yang telah diidentifikasikan berdasarkan domain PO1, PO2, PO3, PO4, Al1, Al2, DS1, DS2, DS3, DS5, DS9, DS11, DS13.

\subsection{Identifikasi Sistem Inventory PT. Domino's Pizza}

Adapun ruang lingkup proses sistem informasi inventory pada PT. Domino's Pizza dengan standar COBIT 4.1 yang telah diolah sesuai dengan studi kasus adalah sebagai berikut:

Tabel 2. Ruang Lingkup Audit SI Inventory PT.Domino;s Pizza

\begin{tabular}{|c|c|l|}
\hline Domain & $\begin{array}{c}\text { Sub } \\
\text { Domain }\end{array}$ & \multicolumn{1}{c|}{ Description } \\
\hline \multirow{4}{*}{ PO } & PO 01 & Define a Strategic IT Plan \\
\cline { 2 - 3 } & PO 02 & Define the Information Architecture \\
\cline { 2 - 3 } & PO 03 & Determine Technological Direction \\
\cline { 2 - 3 } & PO 04 & $\begin{array}{l}\text { Define the IT Processes, Organization } \\
\text { and Relationship }\end{array}$ \\
\hline \multirow{4}{*}{ Al } & Al 01 & Identify Automated Solutions \\
\cline { 2 - 3 } & Al 02 & $\begin{array}{l}\text { Acquire and Maintain Application } \\
\text { Software }\end{array}$ \\
\hline \multirow{5}{*}{ DS } & DS 01 & Define and Manage Service Levels \\
\cline { 2 - 3 } & DS 02 & Manage Third-Party Services \\
\cline { 2 - 3 } & DS 03 & Manage Performance and Capacity \\
\cline { 2 - 3 } & DS 05 & Ensure System Security \\
\cline { 2 - 3 } & DS 09 & Manage the Configuration \\
\cline { 2 - 3 } & DS 11 & Manage Data \\
\cline { 2 - 3 } & DS 13 & Manage Operations \\
\hline \multirow{4}{*}{ ME } & ME 01 & Monitor and Evaluate IT Performance \\
\cline { 2 - 3 } & ME 02 & Monitor and Evaluate Internal Control \\
\hline
\end{tabular}

Sumber: Hasil Penelitian (2020)

\subsection{Rangkuman Tingkat Kematangan (Maturity Level)}

Tabel 3. Rata-rata Maturity Level Masing-masing Domain

\begin{tabular}{|c|l|r|r|l|}
\hline Domain & Description & $\begin{array}{l}\text { Current } \\
\text { Maturity }\end{array}$ & $\begin{array}{l}\text { Expected } \\
\text { Maturity }\end{array}$ & Keterangan \\
\hline PO 01 & $\begin{array}{l}\text { Define a } \\
\text { Strategic IT } \\
\text { Plan }\end{array}$ & 3,13 & 4,00 & $\begin{array}{l}3 \text {-Defined } \\
\text { Process }\end{array}$ \\
\hline PO 02 & $\begin{array}{l}\text { Define the } \\
\text { Information } \\
\text { Architecture }\end{array}$ & 3,53 & 4,00 & $\begin{array}{l}4- \\
\text { Managed } \\
\text { and } \\
\text { Measurable }\end{array}$ \\
\hline
\end{tabular}




\begin{tabular}{|c|c|c|c|c|}
\hline PO 03 & $\begin{array}{l}\text { Determine } \\
\text { Technological } \\
\text { Direction }\end{array}$ & 3,1 & 4,00 & $\begin{array}{l}3 \text {-Defined } \\
\text { Process }\end{array}$ \\
\hline PO 04 & $\begin{array}{l}\text { Define the IT } \\
\text { Processes, } \\
\text { Organization } \\
\text { and } \\
\text { Relationship }\end{array}$ & 3,2 & 4,00 & $\begin{array}{l}3 \text {-Defined } \\
\text { Process }\end{array}$ \\
\hline AI 01 & $\begin{array}{l}\text { Identify } \\
\text { Automated } \\
\text { Solutions }\end{array}$ & 3,19 & 4,00 & $\begin{array}{l}3 \text {-Defined } \\
\text { Process }\end{array}$ \\
\hline AI 02 & $\begin{array}{l}\text { Acquire and } \\
\text { Maintain } \\
\text { Application } \\
\text { Software }\end{array}$ & 3,18 & 4,00 & $\begin{array}{l}3 \text {-Defined } \\
\text { Process }\end{array}$ \\
\hline DS 01 & $\begin{array}{l}\text { Define and } \\
\text { Manage } \\
\text { Service } \\
\text { Levels }\end{array}$ & 3,12 & 4,00 & $\begin{array}{l}3 \text {-Defined } \\
\text { Process }\end{array}$ \\
\hline DS 02 & $\begin{array}{l}\text { Manage } \\
\text { Third-Party } \\
\text { Services }\end{array}$ & 2,97 & 4,00 & $\begin{array}{l}3 \text { - Defined } \\
\text { Process }\end{array}$ \\
\hline DS 03 & $\begin{array}{l}\text { Manage } \\
\text { Performance } \\
\text { and Capacity }\end{array}$ & 3,42 & 4,00 & $\begin{array}{l}3 \text { - Defined } \\
\text { Process }\end{array}$ \\
\hline DS 05 & $\begin{array}{l}\text { Ensure } \\
\text { System } \\
\text { Security }\end{array}$ & 3,29 & 4,00 & $\begin{array}{l}3 \text { - Defined } \\
\text { Process }\end{array}$ \\
\hline DS 09 & $\begin{array}{l}\text { Manage the } \\
\text { Configuration }\end{array}$ & 2,80 & 4,00 & $\begin{array}{l}3-\text { Defined } \\
\text { Process }\end{array}$ \\
\hline DS 11 & Manage Data & 3,16 & 4,00 & $\begin{array}{l}3-\text { Defined } \\
\text { Process }\end{array}$ \\
\hline DS 13 & $\begin{array}{l}\text { Manage } \\
\text { Operations }\end{array}$ & 3,19 & 4,00 & $\begin{array}{l}3-\text { Defined } \\
\text { Process }\end{array}$ \\
\hline ME 01 & $\begin{array}{l}\text { Monitor and } \\
\text { Evaluate IT } \\
\text { Performance }\end{array}$ & 3,70 & 4,00 & $\begin{array}{l}4- \\
\text { Managed } \\
\text { and } \\
\text { Measurable }\end{array}$ \\
\hline ME 02 & $\begin{array}{l}\text { Monitor and } \\
\text { Evaluate } \\
\text { Internal } \\
\text { Control }\end{array}$ & 3,40 & 4,00 & $\begin{array}{l}3 \text {-Defined } \\
\text { Process }\end{array}$ \\
\hline \multicolumn{2}{|c|}{ Rata-Rata } & 3,23 & 4,00 & $\begin{array}{l}\text { 3-Defined } \\
\text { Process }\end{array}$ \\
\hline
\end{tabular}

Sumber: Hasil Penelitian (2020)

Dari hasil perhitungan didapatkan rata-rata nilai domain sistem informasi inventory sebesar 3,23. Dari nilai tersebut, dapat ditarik kesimpulan bahwa sistem informasi inventory pada PT. Domino's Pizza berada pada level Defined Process dengan keterangan prosedur distandarisasi dan didokumentasikan kemudian dikomunikasikan melalui pelatihan. Kemudian diamanatkan bahwa proses-proses tersebut harus diikuti. Namun penyimpangan tidak mungkin dapat terdeteksi. Menurut penelitian penulis, prosedur sendiri tidak lengkap namun sudah memformalkan praktek yang berjalan dan proses standar dalam praktik pelaksanaan kegiatan sistem inventory sebagian telah didokumentasikan, proses ini didasari pada proses pengembangan sistem yang telah diintegrasikan. Proses-proses ini digunakan untuk membantu manejer, ketua tim dan anggota tim pengembangan sehingga dapat bekerja dengan lebih efektif. Aturan dan tanggung jawab yang sudah sebagian diidentifikasikan dengan jelas dan mudah dimengerti. Karena proses perangkat lunak belum seluruhnya didefinisikan dengan jelas, maka manajemen mempunyai pengatahuan yang belum seluruhnya lengkap mengenai kemajuan sistem inventory yang ada. Biaya, jadwal dan kebutuhan sistem dalam pengawasan dan kualitas sistem yang diawasi. Meskipun demikian sistem informasi inventory pada PT. Domino's Pizza berada dikematangan level yang standar dalam sistem informasi inventory pada perusahaan ritel, namun belum sepenuhnya terpenuhi dengan harapan yang tinggi (Expectation) dari pihak

REPOSITOR, Vol. 2, No. 10, Oktober 2020, Pp. 1359-1367 
perusahaan. Level ini masih pada transisi antara Defined Process menuju Managed and Measurable.

Pada domain PO2 dan ME1 telah mencapai level yang sesuai dengan ekpektasi perusahaan. Oleh karena itu PT. Domino's Pizza dapat lebih lagi meningkatkan proses manajemen dalam mengembangankan proyek yang ada dan yang telah direncanakan agar organisasi dapat berhasil dalam mengembangkan sistem yang sudah ada sebelumnya, walaupun terdapat proses tertentu yang tidak sama. Tingkat efektif suatu proses sistem informasi inventory mempunyai karakteristik seperti; practiced, dokumentasi, enforced, trained, measured, dan yang dapat ditingkatkan. Product requirement dan dokumentasi perancangan agar selalu dijaga supaya dapat mencegah perubahan yang tidak diinginkan (preventive).

\subsection{Nilai Kesenjangan Kematangan Saat ini (Current Maturity)}

kematangan (maturity) sistem informasi inventory pada PT. Domino's Pizza saat ini sebesar 3,23 maka dilakukan analisis kesenjangan terhadap expected maturity yaitu sebesar 4. Analisa ini diharapkan dapat memberikan kemudahan bagi pengelolaan sistem informasi inventory yang serasi diantara ke-4 domain. Alasan nilai yang ingin dicapai sebesar 4 adalah melihat kesiapan pada PT. Domino's Pizza dalam manajemen, persediaan, pengelolaa TI, pengelolaan SDM, pengelolaan keuangan dan pelayanan sehingga dalam perbaikan dan pengembangan sistem informasi yang lebih efektif menjadi terbatas. Pada sub-domain lain yaitu PO1, PO2, PO3, PO4, AI1, AI2, DS1, DS2, DS3, DS5, DS9, DS11, DS13, ME1, ME2 telah mencapai level 3. Tabel dibawah ini menunjukkan gap/selisih antara current maturity dengan expexted maturity;

Tabel 4. Perbandingan Current Maturity, Expected Maturity dan Gap / Selisih

\begin{tabular}{|c|c|c|c|}
\hline \multirow{2}{*}{ Domain } & \multicolumn{3}{|c|}{ MaturityLevel } \\
\cline { 2 - 4 } & $\begin{array}{c}\text { Current } \\
\text { Maturity }\end{array}$ & $\begin{array}{c}\text { Expected } \\
\text { Maturity }\end{array}$ & Gap/ Selisih \\
\hline PO 01 & 3,13 & 4,00 & 0,87 \\
\hline PO 02 & 3,53 & 4,00 & 0,47 \\
\hline PO 03 & 3,10 & 4,00 & 0,90 \\
\hline PO 04 & 3,20 & 4,00 & 0,80 \\
\hline AI 01 & 3,19 & 4,00 & 0,81 \\
\hline AI 02 & 3,18 & 4,00 & 0,82 \\
\hline DS 01 & 3,12 & 4,00 & 0,88 \\
\hline DS 02 & 2,97 & 4,00 & 1,03 \\
\hline DS 03 & 3,42 & 4,00 & 0,58 \\
\hline DS 05 & 3,29 & 4,00 & 0,71 \\
\hline DS 09 & 2,80 & 4,00 & 1,20 \\
\hline DS 11 & 3,16 & 4,00 & 0,84 \\
\hline DS 13 & 3,19 & 4,00 & 0,81 \\
\hline ME 01 & 3,70 & 4,00 & 0,30 \\
\hline ME 02 & 3,40 & 4,00 & 0,60 \\
\hline Rata- & $\mathbf{3 , 2 3}$ & $\mathbf{4 , 0 0}$ & $\mathbf{0 , 7 7}$ \\
\hline Rata & & & \\
\hline
\end{tabular}

Sumber: Hasil Penelitian (2020)

Dari hasil tabel perhitungan terebut terdapat jarak 0.77 pada domain PO, AI, DS dan ME, antara expected maturity dengan current maturity. Walaupun gap terbilang kecil tetapi dibutuhkan penyesuaian pada masing-masing domain karena nilai 0.77 adalah nilai 
rata-rata perdomain, maka diperlukannya rekomendasi pada bagian sub-domain DS9 karena didapatkan hasil terendah sehingga perbaikan lebih fokus pada bagian domain yang lemah.

Perbedaan kondisi kesenjangan sistem informasi inventory PT. Domino's Pizza dengan menggunakan domain COBIT 4.1 yaitu PO1, PO2, PO3, PO4, AI1, AI2, DS1, DS2, DS3, DS5, DS9, DS11, DS13, ME1, ME2 yang dipakai pada ruang lingkup terhadap current maturity dengan expected maturity dapat dilihat seperti pada gambar dibawah ini;

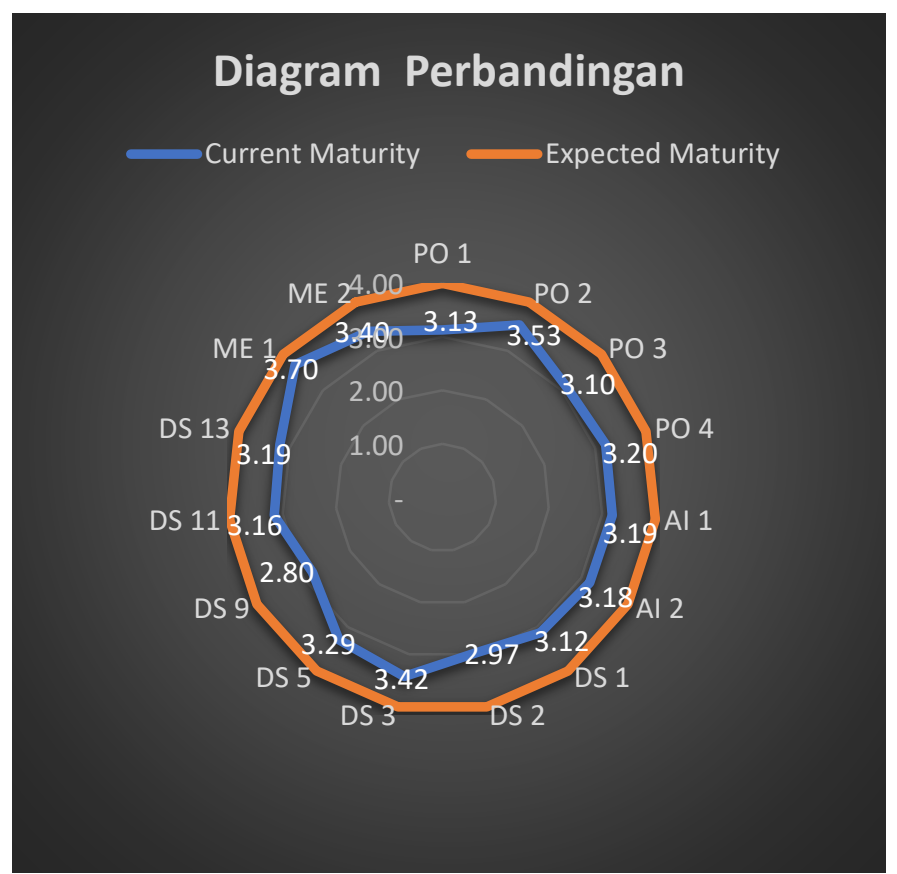

Sumber: Hasil Penelitian (2020)

\section{Gambar 2. Perbandingan Current Maturity dengan Expected Maturity}

\section{Kesimpulan}

Dari hasil penelitian diatas, dapat diketahui bahwa analisis tingkat kematangan yang dihasilkan mendapatkan nilai sebesar 3,23 dengan selisih 0,77 dari tingkat kematangan yang diharapkan sebesar 4,00. Angka yang didapatkan berdasarkan hasil pengelolaan kuesioner tersebut berada pada level 3 Defined Process yang artinya penerapan sistem inventory pada Domino's Pizza telah dilakukan tetapi masih memerlukan proses tata kelola IT secara rutin dan dengan pengawasan dari pihak manajemen atau kepala divisi yang bertugas dilapangan.

\section{Refrensi}

[1] D. F. Saefudin and M. Informatika, "Analisa Dan Perancangan Aplikasi Persediaan Obat Studi Kasus : Klinik Umum,” vol. XX, no. 1, 2018.

[2] R. Anderson, J. F. Andry, J. S. Informasi, F. Teknologi, and U. B. Mulia, "Audit Aplikasi Inventori Menggunakan Framework Cobit 4 . 1 Pada Store Nonna," vol. 3, no. 1, pp. 112, 2018.

[3] E. Zuraidah, "Audit Sistem Informasi Inventory Pada PT DSSS dengan Menggunakan Framework Cobit 4 . 1," Semin. Nas. Inov. dan Tren 2018, pp. 47-54, 2018.

[4] S. Wiyandari and N. Pohan, "JUSTI - Jurnal Sains dan Teknologi Informasi," J. Sains dan Teknol. Inform., vol. I, no. I, pp. 1-5, 2019. 
[5] Tim Penyusun Modul, "Dasar-dasar Audit Internal Sektor Publik," 2007.

[6] W. Wella and J. Setiawan, "Audit Sistem Informasi Menggunakan Cobit 4.1 pada PT. Erajaya Swasembada, Tbk.," J. Ultim. InfoSys, vol. 6, no. 2, pp. 111-124, 2016.

[7] I. Syarif and Mustagfirin, "Sistem Informasi Inventory Barang Pada Apotek Sultan Menggunakan Metode FIFO," J. IIm. Cendekia Eksakta, pp. 119-125, 2018.

[8] M. Fadly, D. Suhendro, and A. Syahputra, "Perancangan Aplikasi Persediaan Barang dan Bahan Makanan Menggunakan Metode FIFO pada KFC Pematangsiantar," J. IIm. Media Sisfo, vol. 13, no. 1, p. 48, 2019.

[9] dan A. S. Abdul Hakim, Hoga Saragih, "EVALUASI TATA KELOLA TEKNOLOGI INFORMASI DENGAN FRAMEWORK COBIT 5 DI KEMENTERIAN ESDM (Studi Kasus pada Pusat Data dan Teknologi Informasi ESDM)," J. Sist. Inf. (Journal Inf. Syst. 2/10 (2014), 108-117 DOI http//dx.doi.org/10.21609/jsi.v10i2.393, vol. 10, no. Vol 10 No 2 (2014): Jurnal Sistem Informasi (Journal of Information System), pp. 1-10, 2015.

[10] J. F. Andry, Y. M. Geasela, A. Wailan, B. A. Matjik, A. Kurniawan, and J. Junior, "Penggunaan COBIT 4.1 Dengan Domain ME Pada Sistem Informasi Absensi (Studi Kasus: Universitas XYZ)," Inform. Mulawarman J. IIm. IImu Komput., vol. 13, no. 2, p. 97, 2019.

[12] C. K. Gunawan, A. Chandra, M. Khotama, J. Osmond, and J. F. Andry, "Audit Fingerprint pada PT X dengan Framework COBIT 4.1," J. Inform. dan Sist. Inf. Univ. Ciputra, vol. Vol. 04, N, no. October, pp. 34-43, 2018.

[11] I. B. Sukmajaya and J. F. Andry, "AUDIT SISTEM INFORMASI PADA APLIKASI ACCURATE MENGGUNAKAN MODEL COBIT FRAMEWORK 4.1 (Studi kasus Pt. Setia Jaya Tekhnologi)," Semin. Nas., vol. 2, no. 2502, pp. 1-45, 2017. 